\title{
ESTIMATING THERMAL STABILITY OF PHOSPHATED AND PHOSPHATED SULFATED MESOPOROUS ZIRCONIA
}

\author{
Phong Pham Van ${ }^{1}$, Khanh Dieu Hong Nguyen ${ }^{2, *}$ \\ ${ }^{1}$ Vietnam National Oil and Gas Group, 18 Lang Ha Street, Ba Dinh, Hanoi \\ ${ }^{2}$ Hanoi University of Science and Technology, 1 Dai Co Viet Street, Hai Ba Trung, Hanoi \\ "Email: dieuhong_bk@yahoo.com
}

Received: 29 January 2016; Accepted for publication: 15 September 2016

\begin{abstract}
Mesoporous phosphated zirconia (m-PZ) and mesoporous phosphated sulfated zirconia (mPSZ) were synthesized through condensation methods using $\mathrm{Zr}_{3}\left(\mathrm{PO}_{4}\right)_{4}$ and $\mathrm{Zr}\left(\mathrm{SO}_{4}\right)_{2}$ as precursors, respectively. The precursors, solvents with suitable molar or mass ratios were mixed at $100{ }^{\circ} \mathrm{C}$ for 48 hours to obtain the mesoporous channels. An oxophosphate process was used to synthesize the m-PSZ material for improving its thermal stability. Some techniques were used to characterize the materials such as SAXRD, TG-DTA and TEM.
\end{abstract}

Keywords: mesoporous, zirconia, oxophosphate, thermal stability.

\section{INTRODUCTION}

The synthesis of MCM-41, a silica with a hexagonal arrangement of cylindrical pores, the sizes of which are adjustable from 2 to $10 \mathrm{~nm}$, and related materials [1] has stimulated a considerable amount of interest in this new class of mesoporous materials. Shortly after its synthesis, different mechanisms were developed to explain the formation of this porous material [2]. The mechanism suggested by Monnier et al. [2] implies the possibility of substituting the silicate with other metal oxides to prepare a wide range of mesostructured oxidic materials. Subsequently, mesostructured surfactant composites of tungsten oxide, antimony oxide, and other metal oxides have been synthesized [3, 4]. However, a major problem of these nonsiliceous materials is the removal of the template: it was neither possible to remove the surfactant by conventional methods like calcination or extraction nor by oxygen plasma calcination without destroying the pore structure. An exception is the recently described mesoporous $\mathrm{TiO}$, in which the hexagonal pore structure remains stable even after calcination, but the BET surface area is only about $200 \mathrm{~m}^{2} / \mathrm{g}$ [5]. The thermal instability of the mesostructured metal oxide composites is probably due to the different oxo chemistry of the metals in comparison with silicon. For instance, the walls in the tungsten oxide surfactant composite are formed by Keggin ions, and a complete condensation seems improbable [6]. Another reason is probably the existence of several relatively stable oxidation states of the metal centers. Thus, during the calcination, reduction by the surfactant and/or oxidation by air oxygen could occur leading to structural collapse. 
Mesoporous sulfated zirconia (m-SZ) was also a kind of the metal oxide derived mesostructured material exhibiting its high surface area, superacid sites, and it was a good potential for widening applications of the traditional zirconia based acid materials. The major problem for synthesizing the $\mathrm{m}$-SZ material still belonged to its low thermal stability leading to collapse the mesopores during the template removal at high temperature.

One of the best solution for improving the thermal stability of the m-SZ material was to change its surface state through the oxophosphate process. In which, the oxophosphate groups could be used to lock the $-\mathrm{OH}$ groups attached on the zirconium sites; therefore the zirconium site could ensure its oxidation state during the calcination.

In a previous paper, the $\mathrm{m}$-SZ material was synthesized through condensation method in alkaline solution [7]. This study considered the two oxophosphate procedures for enhancing the thermal stability of the m-SZ material established before and after the sulfatation of the zirconia.

\section{EXPERIMENTALS}

\subsection{Chemicals}

Zirconyl chloride $\left(\mathrm{ZrOCl}_{2} .8 \mathrm{H}_{2} \mathrm{O}\right)$, cetyltrimethylammonium bromide (CTAB), sulfuric acid $\left(\mathrm{H}_{2} \mathrm{SO}_{4}\right)$, ammonia solution were all purchased from Merck and used as received; deodorizer distillate collected from the Cailan Vegetable Refinery in Quang Ninh province, Vietnam was pretreated by heating up to $120{ }^{\circ} \mathrm{C}$ for 2 hours to complete water removal before used; distilled water was prepared in our own laboratory.

\subsection{Preparation of mesoporous sulfated zirconia}

Mesoporous sulfated zirconia (m-SZ) was prepared by two-step procedure including making $\mathrm{Zr}\left(\mathrm{SO}_{4}\right)_{2}$ precursor followed by gradual precipitation and condensation of the $\mathrm{Zr}(\mathrm{OH})_{4}$ portions on the surfactant micelles (CTAB). The whole process was based on a study in a previous paper [7].

\subsection{Oxophosphate processes}

The oxophosphate processes were established through two methods as following described:

\subsubsection{Synthesizing the mesoporous phosphated zirconia}

4.1284 grams of $\mathrm{ZrOCl}_{2} .8 \mathrm{H}_{2} \mathrm{O}$ were dissolved in $100 \mathrm{ml}$ of distilled water followed by gentle stirring to form a homogeneous solution A. A certain volume of ammonia solution $25 \% \mathrm{wt}$ was dropped wise into the solution A to completely precipitate zirconium hydroxide $\operatorname{Zr}(\mathrm{OH})_{4}$. The zirconium hydroxide was then washed throughoutly by the distilled water until the $\mathrm{pH}$ of the waste water became neutral. The precipitate $\mathrm{Zr}(\mathrm{OH})_{4}$ was dissolved again in an excess volume of $\mathrm{H}_{3} \mathrm{PO}_{4}$ solution to form $\mathrm{Zr}_{3}\left(\mathrm{PO}_{4}\right)_{4}$ solution at $\mathrm{pH}$ ranging from 3 to 5. Then A precise amount of $\mathrm{CTAB}$ was dissolved in $100 \mathrm{ml}$ of distilled water followed by pouring this solution into the $\mathrm{Zr}\left(\mathrm{SO}_{4}\right)_{2}$ solution to form solution $\mathrm{B}$. The solution $\mathrm{B}$ was stirred vigorously and heated to $100^{\circ} \mathrm{C}$ and aged for 48 hours to maintain the condensation reaction of the precursor on the CTAB micelles. The precipitate was then filtered to remove resident acid, dried at $110{ }^{\circ} \mathrm{C}$ for 12 hours to evaporate surface water and calcined at $450{ }^{\circ} \mathrm{C}$ for 4 hours to eliminate the CTAB obtaing the mesoporous phosphated zirconia (m-PZ). 


\subsubsection{Oxophosphate process of the $m$-SZ material}

The m-SZ material was sinked into $20 \mathrm{ml}$ solution of $\mathrm{H}_{3} \mathrm{PO}_{4} 1 \mathrm{M}$ in combination with well stirring. The mixture was maintained for 24 hours at ambient temperature; then the precipitate was filtered and dried at $110{ }^{\circ} \mathrm{C}$ overnight. This dried powder was then calcinated at $450{ }^{\circ} \mathrm{C}$ for 6 hours to obtain mesoporous oxophosphated sulfated zirconia (m-PSZ).

\subsection{Characterizations}

Powder XRD of the samples were recorded on a D8 Advance Bruker diffractometer using $\mathrm{Cu} \mathrm{K} \alpha(\lambda=0.15406)$ radiation with two techniques such as small and wide angle. TG-DTA was measured on NETZSCH STA 409 PC/PG. TEM images were recorded on a JEM1010-JEOL TEM operated at $80 \mathrm{kV}$.

\section{RESULTS AND DISCUSSION}

\subsection{TG-DTA analysis}

The m-PZ and m-PSZ samples before the calcinations could be estimated their thermal behaviors through TG-DTA analysis; then the results indicated the thermal stability of each material. Fig. 1 and Fig. 2 showed the TG-DTA diagram of the m-PZ and m-PSZ materials.

The TG-DTA analysis results of the m-PZ and m-PSZ materials showed three ranges of weight loss including processes occurred during the calcinations such as water removal, template (CTAB) decomposition under heated air and hydroxyl group condensations. For instance, the TG-DTA curves of the m-PZ material showed an endothermic peak at $\sim 100{ }^{\circ} \mathrm{C}$ of the water removal, a group of exothermic peaks at $\sim 400{ }^{\circ} \mathrm{C}$ of the template decomposition, and an exothermic peak at $\sim 550{ }^{\circ} \mathrm{C}$ of the mesostructured collapse corresponding to the weight loss of $\sim 1.5 \mathrm{mg}, \sim 4.5 \mathrm{mg}$ and $\sim 0.5 \mathrm{mg}$, respectively.

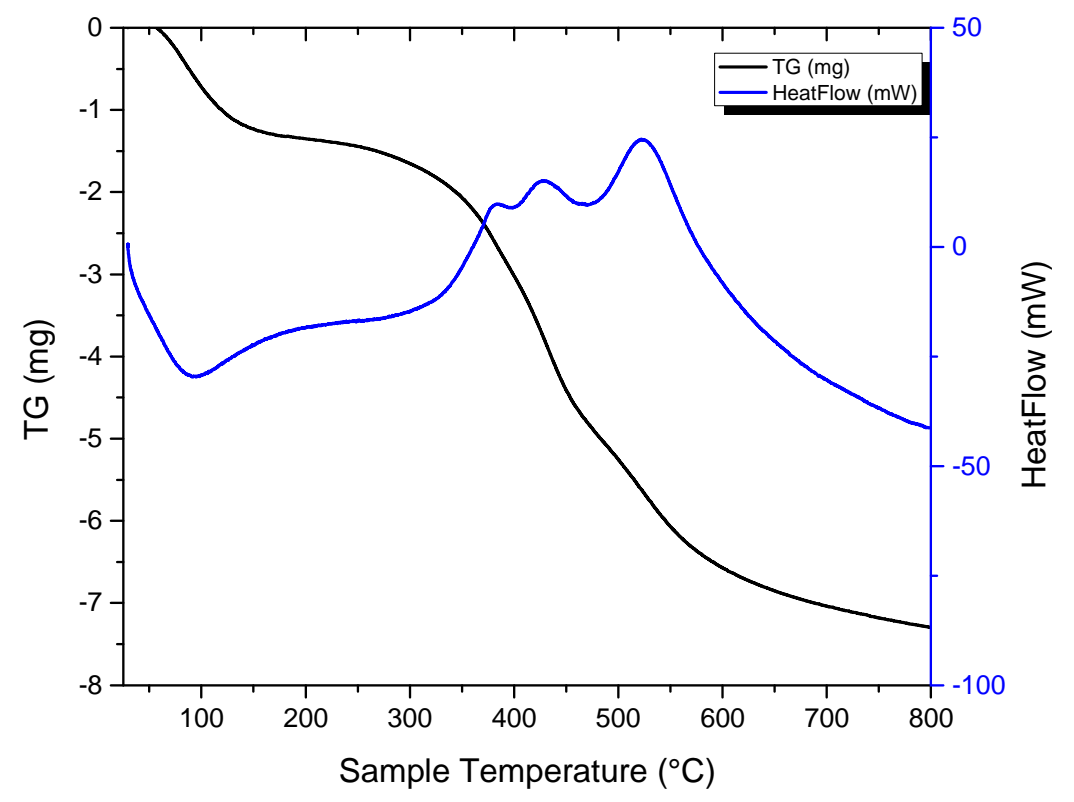

Figure 1. TG-DTA diagram of m-PZ material. 


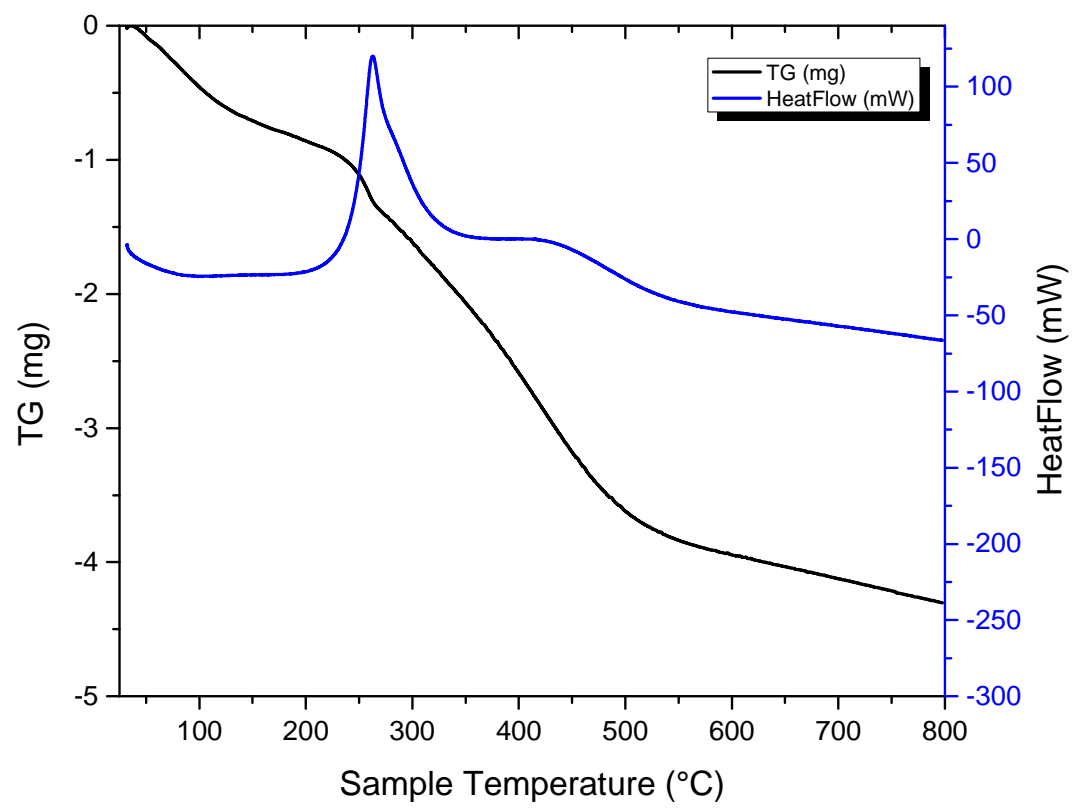

Figure 2. TG-DTA diagram of m-PSZ material.

There were some differences in the TG-DTA analysis of the m-PSZ material. For instance, the TG-DTA results showed an exothermic peak at $\sim 290{ }^{\circ} \mathrm{C}$ of the template decomposition, a small exothermic peak at $450{ }^{\circ} \mathrm{C}$ of the tiny changes in the mesoporous structure. The decomposition temperature of the template was much less than that of the m-PZ material could be assigned for the more difficult condition required for burning the template when using $\mathrm{Zr}_{3}\left(\mathrm{PO}_{4}\right)_{4}$ as precursor instead of $\mathrm{Zr}\left(\mathrm{SO}_{4}\right)_{2}$.

On the other hand, the intensity of the exothermic peaks responded for the mesoporous collapse in the m-PZ were much higher and clearer than that of the m-PZS material, so it could be said that the thermal stability of the m-PSZ was higher than that of the $\mathrm{m}-\mathrm{PZ}$.

\subsection{XRD patterns}

Small angle X-Ray diffraction (SAXRD) technique was used to characterize the mesoporous structure of the $\mathrm{m}-\mathrm{PZ}$ and $\mathrm{m}-\mathrm{PSZ}$ materials because of finger print peaks appeared assigned for (100), (110)... planes. Figure 3 exhibited the SAXRD patterns of the two materials.

The two materials after calcination at $450^{\circ} \mathrm{C}$ both showed major peaks at $\sim 2.5^{\circ}$ and $\sim 4^{\circ}$ assigned for (100) and (110) planes in the mesoporous structure respectively. The intensity of peaks of the m-PSZ was higher than that of the m-PZ indicating the more ordered structure of the m-PSZ than that of the m-PZ. On the other aspect, it was to say that the mesostructure of the $\mathrm{m}$-PZS was more stable than that of the m-PZ. The reason for that phenomenon could be ascribed for the oxophosphate process established with the m-SZ to form the m-PSZ material while the phosphate groups were directly used as precursor at $\mathrm{m}-\mathrm{PZ}$ material. The presence of phosphate and sulfate ions causes a crystallization delay of the amorphous zirconia phase. Therefore, by stabilizing the amorphous phase, the mesostructures are thermally stable up to 450 ${ }^{\circ} \mathrm{C}$ without loosing their ordered pore structure and their high surface area [8]. 
The effect of phosphate groups in the oxophosphate process was also described in elsewhere papers [1 - 3]. They trustfully confirmed that when introducing the phosphate groups into the mesoporous zirconia, the phosphate groups could link to the surface $-\mathrm{OH}$ groups attached on zirconium sites, improve the crosslingking of this group within the mesoporous structure. The consequence was to stabilize the oxidation state and amorphous phase during the calcination at high temperature.

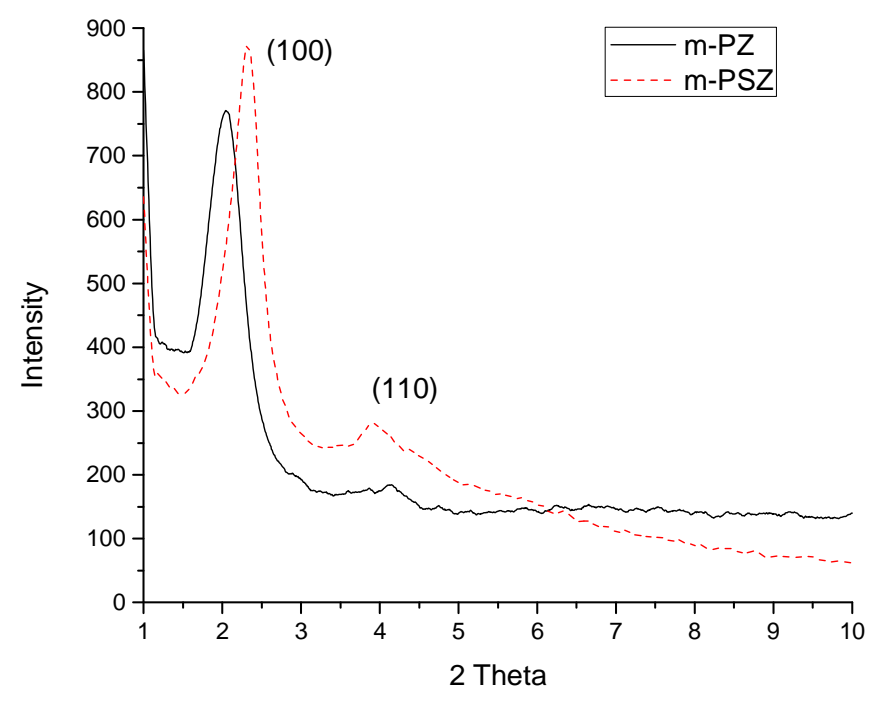

Figure 3. SAXRD patterns of m-PZ and m-PSZ materials.

The thermal stability improvement played an important role for applications of the mesoporous zirconia materials as catalysts for many chemical reactions, because the templates had to be removed after the preparations for activating its catalytic properties.

The SAXRD patterns were the same as some typical mesoporous materials such as MCM41 or SBA-15 which all exhibiting the ordered mesostructure frameworks [8], so it could be assigned for the hexagonal ordered structure appeared in the m-PZ and m-PSZ materials.

\subsection{TEM images}

Figures 4 and Fig. 5 showed the TEM images of the m-PZ and m-PSZ materials, respectively. The two images confirmed the results obtained from the SAXRD patterns which indicate the fomulations of the mesoporous channels in the two materials.

The TEM image of the m-PZ showed tiny mesostructure channels in each material particles. This structure expanded the applications of this kind of material because of enhancing the diffusion potential of the chemical to the active sites located on the material surfaces. In fact there were some applications using the mesoporous zirconia based catalysts [8].

The TEM image of the m-PSZ showed more considerable clear mesoporous channels than that of the m-PZ material. This results may be caused by the more ordered mesostructure within the $\mathrm{m}-\mathrm{PSZ}$ than that of the $\mathrm{m}-\mathrm{PZ}$. Both the $\mathrm{m}-\mathrm{PSZ}$ and $\mathrm{m}-\mathrm{PZ}$ materials may be the potential catalyst candidates for the biodiesel synthesis from rich fatty acid oil and fat, and the results obtained from this applications were published in the future. 


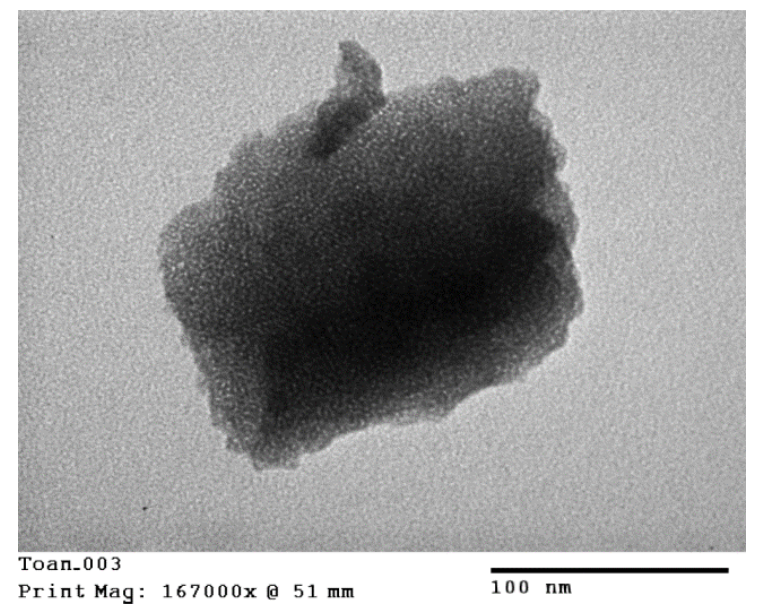

Figure 4. TEM image of m-PZ.

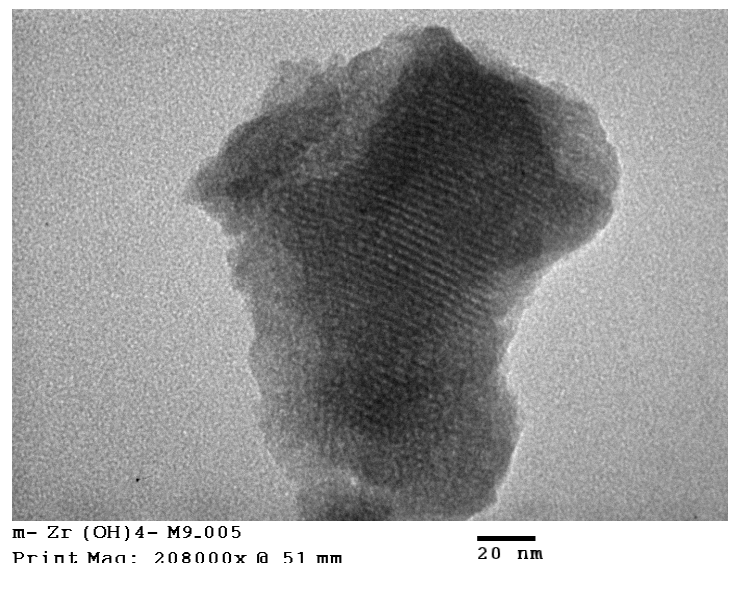

Figure 5. TEM image of m-PSZ.

\section{CONCLUSION}

Both mesoporous phosphate zirconia (m-PZ) and mesoporous phosphated sulfated zirconia (m-PSZ) possessed high ordered mesostructure formed by zirconia framework. Because the oxophosphate procedure was applied to the m-PSZ, its thermal stability was higher than that of the m-PZ material prepared by using $\mathrm{Zr}_{3}\left(\mathrm{PO}_{4}\right)_{4}$. So it was highly recommended that the oxophosphate process could be useful for improving the thermal stability of the zirconia based mesoporous structure materials.

\section{REFERENCES}

1. Kresge C. T., Leonowicz M. E., Roth W. J., Vartuli J. C., Beck J. S. - Ordered mesoporous molecular sieves synthesized by a liquid-crystal template mechanism, Nature 359 (1992) $710-712$.

2. Monnier A., Schuth F., Huo Q., Kumar D., Margolese D, Maxwell R. S., Stucky G. D., Krishnamurty M., Petroff P., Firouzi A., Janicke M., Chmelka B. F. - Cooperative Formation of Inorganic-Organic Interfaces in the Synthesis of Silicate Mesostructures, Science 261 (1993) 1299-1303.

3. Ciesla U., Demuth D., Leon R., Petroff P., Stucky G. D., Unger K., Schiith F. - Surfactant Controlled Preparation of Mesostructured Transition-Metal Oxide Compounds, J. Chem. Sol Chem. Commun. (1994) 1387-1388. 
4. Huo Q., Margolese D. L., Ciesla U., Feng P., Gier T. E., Sieger P., Leon R., Petroff P. M., Schiith F., Stucky G. D. - Generalized synthesis of periodic surfactant/inorganic composite materials, Nature 368 (1994) 317-321.

5. Antonelli D. M., Ying J. Y. - Synthesis of Hexagonally Packed Mesoporous TiO2 by a Modified Sol-Gel Method, Angew. Chem. Inr. Ed. Engl. 34 (1995) 2014-2017.

6. Stein A., Fendorf M., Jarvie T. P., Mueller K. T., Benesi A. J., Mallouk T. E. - Salt-Gel Synthesis of Porous Transition Metal Oxides, Chmm. Murcr. 7 (1995) 304-313.

7. Hong Khanh Dieu Nguyen, Phong Van Pham, Don Ngoc Ta, Ngo Thi Dinh - Preparation of solid superacid catalyst based on mesoporous sulfated zirconia, using for converting deodorizer distillate of vegetable oil to biodiesel, 8RCChE-7VNCC-2VNCCE Proceeding, Hanoi University of Science and Technology (2015).

8. Ulrike Ciesla, Galen Stucky, Ferdi Schtith - Improvement of the Thermal Stability of Mesostructured Metal Oxides with Zirconia as the Example, Mesoporous Molecular Sieves 1998, Studies in Surface Science and Catalysis 117 (1998) 527-534.

\title{
TÓM TẮT
}

\section{NGHIÊN CÚU TÍNH ỔN ĐỊNH NHIẸT CỦA ZICONI OXIT DẠNG MAO QUẢN TRUNG BÌNH SUNFAT HÓA VÀ PHOTPHAT HÓA}

\author{
Phạm Văn Phong ${ }^{1}$, Nguyễn Khánh Diệu Hồng ${ }^{2, * *}$ \\ ${ }^{I}$ Tập đoàn Dầu khí Quốc gia Việt Nam, số 18 Láng Hạ, quận Ba Đình, Hà Nội \\ ${ }^{2}$ Đại học Bách khoa Hà Nội, số 1 Đại Cồ Việt, quận Hai Bà Trung, Hà Nội \\ *Email: dieuhong bk@yahoo.com
}

Nghiên cứu này tổng hợp các vật liệu ziconi oxit dạng mao quản trung bình photphat hóa và sunfat photphat hóa đi từ các tiền chất $\mathrm{Zr}_{3}\left(\mathrm{PO}_{4}\right)_{4}$ và $\mathrm{Zr}\left(\mathrm{SO}_{4}\right)_{2}$ (lần lượt ký hiệu là $\mathrm{m}-\mathrm{PZ}$ và $\mathrm{m}$ $\mathrm{PSZ}$ ). Quá trình tổng hợp các vật liệu được thực hiện ở $100{ }^{\circ} \mathrm{C}$ trong thời gian 48 giờ để tạo ra cấu trúc mao quản trung bình, sau đó vật liệu $\mathrm{m}-\mathrm{PZ}$ được oxophotphat hóa nhằm nâng cao tính ổn định nhiệt của cấu trúc mao quản trung bình. Các phương pháp phân tích hóa lý được sử dụng bao gồm XRD góc hẹp (SAXRD), TG-DTA và TEM.

Tù khóa: mao quản trung bình, ziconi oxit, oxophotphate hóa, tính ổn định nhiệt. 